\title{
The Role of Uncertainty Avoidance on E-Commerce Acceptance across Cultures
}

\author{
Zakariya Belkhamza $^{1} \&$ Syed Azizi Wafa ${ }^{1}$ \\ ${ }^{1}$ School of Business and Economics, Universiti Malaysia Sabah, Malaysia \\ Correspondence: Zakariya Belkhamza. Jalan UMS, Kota Kinabalu, 88400 Sabah, Malaysia. E-mail: \\ zakariya@ums.edu.my
}

Received: November 22, 2013

Accepted: February 27, 2014

Online Published: April 24, 2014

doi: $10.5539 /$ ibr.v7n5p166

URL: http://dx.doi.org/10.5539/ibr.v7n5p166

\begin{abstract}
As organizations embrace the global business world, the exploitation of the recent advance technologies to communicate between various business partners and customers in different geographical locations worldwide and across countries become eminent. The objective of this paper is to advance our understanding on how e-commerce is being adopted in two different countries rarely studied; Malaysia and Algeria, and how one of the Hofstede's cultural dimensions, uncertainty avoidance, makes a difference on this adoption. This paper also aims to provide new empirical evidence in the field of cross-cultural e-commerce adoption. This was done by investigating the relationship between perceived usefulness, attitude, and subjective norm in order to assess the differences of behavioral intentions to use e-commerce in the two countries. Results show that uncertainty avoidance still plays an important role across culture in the e-commerce adoption.
\end{abstract}

Keywords: e-commerce, technology acceptance model, uncertainty avoidance, cross-culture studies, behavioral intention

\section{Introduction}

Many business organizations in this digital age are still striving to move beyond their geographical boundaries and embrace international markets in other countries. Studies on cross-culture in e-commerce adoption are still catching the attention of many researchers (Smith et al., 2013). Organizations are now realizing the importance of cross cultural relations in their operations across countries, taking these relations as one of the success factors for international business performed either through the traditional activities, or thought the digital means of the latest technologies and e-commerce systems. These relations are also important when e-commerce activities are needed across widespread locations within or across countries, especially when the Internet is currently being used by nearly $27 \%$ of the world's population (Howe, 2012).

In order to better understand the social nature e-commerce functions globally, this paper examines the cultural factor using Hofstede's $(1980,1991)$ cultural dimensions. Thus, the objective of this paper is to provide an empirical justification on what factors could affect the behavioral intention of e-commerce usage, and how does national culture influence the behavioral intention to use e-commerce in two different countries, Malaysia and Algeria. These two countries were chosen because of the clear dissimilarity they represent on the dimension of uncertainty avoidance (Al Kailani \& Kumar, 2011). The lack of studies investigating these two cultures is also one of the motivations to conduct this study. Following Hofstede Cultural Index score, Malaysia is moderate to low on uncertainty avoidance, while Algeria is considered having high uncertainty avoidance, being part of the Arab world as illustrated in Table 1. It is believed that uncertainty avoidance may have a moderating impact on the intentions to adopt e-commerce in both countries and also have an impact on how each culture adopt e-commerce.

Table 1. Cultural index scores (Hofstede 1980, 2001)

\begin{tabular}{cc}
\hline Country & Uncertainty Avoidance \\
\hline Malaysia & 36 \\
Algeria & 68 \\
\hline
\end{tabular}




\section{Conceptual Development}

\subsection{Uncertainty Avoidance}

Uncertainty avoidance is defined as the degree to which people in a culture feel uncomfortable with uncertainty and ambiguity (Hofstede, 1980; Hofstede, 2001). Whilst Hofstede assessed cultural values of a group or multitude, more recent research has argued that individuals also do possess cultural values (McCoy et al., 2005). Thus, although there may be some research trends that distinguish different ethnic groups, it is also possible to characterize individuals as having specific cultural traits. Indeed, individuals from different ethnic groups may share similar cultural values as a result of similar lifestyles and socio-economic backgrounds. McCoy et al. (2005) furthermore argue that when trying to integrate cultural values into the examination of phenomenon such as technology adoption amongst individuals, the assumption of homogeneity amongst a national or ethnic group is not appropriate.

According to Karahanna et al. (2013), previous studies undertaking uncertainty avoidance fall under four main categories: The first category consists of studies that view online shopping as involving inherent risks, in which high uncertainty avoidance generally impacts risk perceptions. The second category investigates how uncertainty avoidance affects the need for adaptation. The third category investigates the effect of uncertainty avoidance on website perceptions, while the last category investigates the linkage between uncertainty avoidance and trust formation. This paper can be considered as a combination between the second and third category, where the element of trust, although not directly measured, can be clearly observed.

In this setting, people in low uncertainty avoidance culture usually prefer situations where they feel they are free and not bound by any rules and regulations. Some previous research showed that uncertainty avoidance has a significant effect on people's behavior (Hofstede \& Bond, 1988, Panina \& Aiello, 2005). This paper incorporates this cultural dimension in an e-commerce adoption model to see if there is any cultural difference between the two countries. This paper contributes to the efforts of applying Hofstede's cultural dimensions in the study of e-commerce adoption. It is hoped that this research provides both theoretical and empirical contributions for exploring the effect of cultural differences on the adoption of IT-based technologies such as e-commerce.

\subsection{Intention to Use E-Commerce}

Many researchers have used technology acceptance model (Davis, 1989) to predict e-commerce behavior based on perceived usefulness and perceived ease of use (Gefen, 2000; Chakraborty et al., 2008; Belkhamza \& Wafa, 2009). As it is well established in the literature, perceived beliefs about behavioral outcomes are good predictors of behavioral intentions regardless of the technology used (Adams et al., 1992; Karahanna \& Straub, 1999; Lederer et al., 2000).

Zwass (1998) identifies intention to involve in online business activities as the consumer's objective to engage in an electronic exchange relationship, such as sharing business information, maintaining relationships, and conducting business transactions. Therefore, online transactions can also be viewed as interactive marketing communications (Stewart \& Pavlou, 2002; Green \& Pearson, 2011; Lim \& Ting, 2012).

\subsection{Perceived Usefulness, Usage Intention and Uncertainty Avoidance}

Perceived usefulness is defined as the extent to which a person believes that using a technology will enhance his/her performance (Davis, 1989). Perceived usefulness is an important construct in the technology acceptance model (TAM), which is used to predict usage and usage intention. Perceived usefulness has also been shown to have a significant influence on both use and intentions to use a technology (Davis, 1989). Taking e-commerce and Internet as a technology, previous studies suggest that consumers with favorable attitudes toward e-commerce were found to perceive online shopping as being useful, due to its ability to enhance shopping productivity and effectiveness (Pavlou \& Stewart, 2000; Lim \& Ting, 2012).

Uncertainty avoidance may be affected by various factors people are generally reinforced with, such as rewards, promotions and bonuses (Schein, 1980; Pfeffer, 1982). This explains why it is believed that in cultures where uncertainty avoidance is high, individuals are uncomfortable with ambiguous and uncertain situations, so uncertainty is usually expected to be less and reduced. Moreover, because the most online transaction activities are performed far from a social presence, the feeling of uncertainty may be present. Consequently, individuals in high uncertainty avoidance culture will be less oriented to involve in such e-commerce activities than those in low uncertainty avoidance culture. Thus, it is hypothesized that:

$H_{I}$ : The relationship between perceived usefulness and e-commerce usage intention is weaker in individuals living in a high uncertainty avoidance culture, compared to those living in a low uncertainty avoidance culture. 


\subsection{Attitude, Usage Intention and Uncertainty Avoidance}

Chai and Pavlou (2004) define attitude in the context of e-commerce as the overall evaluation of the desirability of a potential transaction with a specific e-commerce provider. In this context, most previous research suggests that attitude tends to influence the behavioral intention of individuals. This statement has also been confirmed in many behavioral theories, such as the theory of planned behavior (Ajzen, 1991) and the theory of reasoned action (Fishbein \& Ajzen, 1975). Applying these theories, many empirical studies strongly support this concept of attitude in various cultural contexts. Hence, for a particular individual involved in e-commerce activities, a positive attitude toward e-commerce transaction is suggested to instill confident in the individual in order to facilitate knowledge sharing concerning e-commerce activities and hence facilitate the engagement in online transactions. Favorable attitude is also expected to reduce barriers of engaging and adopting e-commerce activities. Therefore, a positive relationship between attitude and intention to use e-commerce is expected.

As far as cultures are concerned, individuals who live in countries with high uncertainty avoidance such as Algeria usually tend to avoid uncertain situations and rather act under known and recognized conditions. On the contrary, individuals in low uncertainty avoidance culture such as Malaysia are somehow having no much issue on accepting uncertainty conditions and are comfortable with them. Thus, individuals in low uncertainty avoidance culture tend to have an adequate comfort zone toward their attitude and intention to involve in e-commerce activities. Therefore, we hypothesize that:

$\mathrm{H}_{2}$ : The relationship between attitude and e-commerce usage intention is weaker for individuals living in a high uncertainty avoidance culture, compared to those living in a low uncertainty avoidance culture.

\subsection{Subjective Norm, Usage Intention and Uncertainty Avoidance}

According to theory of planned behavior (TPB) (Ajzen, 1991), the intention of an individual to perform an action is a function of what is called a subjective norm, defined as the perceived social pressure whether to perform or not to perform a particular behavior. It is believed that the normative belief of individuals concerning the involvement in e-commerce transaction is influence by their surroundings and social pressure. Previous research shows a positive relationship between subjective norms an e-commerce usage (Pavlou \& Fygenson, 2006). E-commerce users may perceive that their families and friends would prefer to act and behave in a way they may influence their beliefs and ultimately affect their behavioral intention toward e-commerce use (Pavlou \& Chai, 2002). Moreover, Venkatesh and Davis (2000) stated that subjective norm usually has an impact on both perceived usefulness and intention to use. Indeed, people usually tend to act when a peer or influence individual say they should even though they actually do not prefer or believe on that action. In the present research, it is expected that there is a positive relationship between subjective norm and intention to use e-commerce, following previous studies such as Chiasson and Lovato (2001) in which subjective norm is considered a significant antecedent of IT adoption intention.

As some previous research (Choi \& Geistfeld, 2004; Nasco et al., 2008) stated, individuals in low uncertainty avoidance culture such as Malaysia would have strongly link their subjective norm feelings of external influence toward their intention to involve in e-commerce, compared to individuals in high uncertainty avoidance culture, such as Algeria. Thus, we hypothesize that:

$H_{3}$ : The relationship between subjective norm and e-commerce usage intention is weaker for individuals living in a high uncertainty avoidance culture, compared to those living in low uncertainty avoidance culture.

\section{Research Methods}

The sample of this study consists of tourism operators randomly selected from Malaysia and Algeria. For Malaysia, out of the 120 initial participants, 28 questionnaires were undeliverable, 92 responses were returned, with a response rate of $76 \%$. For Algeria, 120 questionnaires were sent. Only 88 questionnaires were returned, making a response rate of $73 \%$. The two rates are acceptable for both samples.

\subsection{Measures Development}

The measures of the variables were adopted from other studies that used the same variables in similar contexts. The intention to use e-commerce items were measured using seven items adapted from Pavlou (2003). Items of perceived usefulness, attitude, and subjective norm were measured using three items each and adopted from Taylor and Todd (1995) and Ndubisi et al. (2001). It was convenience to use those items as most of these items have been used in previous studies and all were found to have an excellent validity and reliability.

\section{Results}

Cronbach's Alpha was computed to examine the reliability of the constructs. Table 2 illustrates that all measures 
have acceptable levels of reliability values of 0.7 for both Malaysia and Algeria. Discriminant and convergent validity were both examined using exploratory factor analysis with a Varimax rotation. Results show that all items were significantly loaded on their respective factors. Results are showed in Table 2.

Table 2. Correlation matrix of principal constructs

\begin{tabular}{lcccc}
\hline & Intention & Perceived usefulness & Attitude & Subjective Norm \\
\hline Intention & 1.000 & $.425^{* *}$ & $.301^{* *}$ & $.244^{* *}$ \\
Perceived usefulness & & 1.000 & $.146^{*}$ & $.189^{* *}$ \\
Attitude & & & 1.000 & $.341^{*}$ \\
Subjective Norm & & & .0001 \\
Cronbach's Alpha & 0.885 & 0.791 & 0.813 & 0.943 \\
\hline
\end{tabular}

Note. ${ }^{* *}$ Correlation is significant at the 0.01 level; * Correlation is significant at the 0.05 level.

\subsection{Hypothesis Testing}

To test the three hypotheses of this study, two linear regression tests were performed. First, data was taken for both countries combined to see whether the measured variables can explain the usage intention of e-commerce. Results of this analysis are illustrated in Table 3. Second, the same test was performed again but applied on the data of each country separately. Tables 4 and 5 show the results of the two countries, Malaysia and Algeria, respectively.

Table 3. Results of regression analysis for data of both countries

\begin{tabular}{|c|c|c|c|c|c|}
\hline & \multicolumn{2}{|c|}{ Unstandardized Coefficients } & \multirow{2}{*}{$\frac{\text { Standardized Coefficients }}{\text { Beta }}$} & \multirow[b]{2}{*}{$t$} & \multirow[b]{2}{*}{ Sig. } \\
\hline & $B$ & Std. Error & & & \\
\hline (Constant) & 1.088 & 0.362 & & 3.008 & 0.003 \\
\hline Perceived usefulness & 0.279 & 0.071 & 0.269 & 3.917 & 0.000 \\
\hline Subjective Norm & 0.279 & 0.083 & 0.241 & 3.339 & 0.001 \\
\hline Attitude & 0.119 & 0.062 & 0.137 & 1.908 & 0.058 \\
\hline
\end{tabular}

Note. Dependent Variable: intention.

In the first hypothesis $\mathrm{H}_{1}$, the relationship between perceived usefulness and e-commerce usage intention is hypothesized to be weaker for individuals who live in a high uncertainty avoidance culture, unlike those living in low uncertainty avoidance culture. Thus, we conclude that $\mathrm{H}_{1}$ is accepted. Taking the data of both countries separately, the results are different. For the Malaysian data, this relationship was found to be statistically significant $(B=0.330, \mathrm{p}=0.000)$, unlike the Algerian data where the relationship was not significant $(B=-0.114$, $\mathrm{p}=0.350$ ).

The second hypothesis $\mathrm{H}_{2}$, we hypothesized that the relationship between subjective norm and e-commerce usage intention may be found weaker for individuals in high uncertainty avoidance culture, compared to those in low uncertainty avoidance culture. As shown in Table 4 and 5, this relationship was found to be significant for the Algerian dataset, but not significant for the Malaysian dataset, leading us to reject $\mathrm{H}_{2}$ (Algeria: $B=0.326$, $\mathrm{p}=0.001$; Malaysia: $B=0.050, \mathrm{p}=0.643$ ).

Finally, we hypothesized that the relationship between attitude and e-commerce usage intention may be found weaker for individuals living in high uncertainty avoidance culture if compared with those living in low uncertainty avoidance culture. The results showed in Tables 4 and 5 reveal that this relationship is not significant for Malaysia $(B=0.105, \mathrm{p}=0.167)$, and significant for Algeria $(B=0.781, \mathrm{p}=0.000)$. Thus, $\mathrm{H}_{3}$ was rejected. 
Table 4. Results of regression analysis of the Malaysian dataset

\begin{tabular}{|c|c|c|c|c|c|}
\hline & \multicolumn{2}{|c|}{ Unstandardized Coefficients } & \multirow{2}{*}{$\frac{\text { Standardized Coefficients }}{\text { Beta }}$} & \multirow[b]{2}{*}{$\mathrm{t}$} & \multirow[b]{2}{*}{ Sig. } \\
\hline & B & Std. Error & & & \\
\hline (Constant) & 1.523 & 0.382 & & 3.983 & 0.000 \\
\hline Perceived usefulness & 0.330 & 0.067 & 0.462 & 4.959 & 0.000 \\
\hline Subjective Norm & 0.050 & 0.108 & 0.052 & 0.465 & 0.643 \\
\hline Attitude & 0.105 & 0.076 & 0.153 & 1.392 & 0.167 \\
\hline
\end{tabular}

Note. Dependent Variable: intention.

Table 5. Results of regression analysis of Algerian dataset

\begin{tabular}{lcccccc}
\hline & \multicolumn{2}{c}{ Unstandardized Coefficients } & \multicolumn{2}{c}{ Standardized Coefficients } & & \multicolumn{2}{c}{ Sig. } \\
\cline { 2 - 5 } & $\mathrm{B}$ & Std. Error & Beta & $\mathrm{t}$ & 0.674 & 0.502 \\
\cline { 2 - 5 } (Constant) & 0.316 & 0.469 & & -0.939 & 0.350 \\
Perceived usefulness & -0.114 & 0.121 & -0.076 & 3.476 & 0.001 \\
Subjective Norm & 0.326 & 0.094 & 0.266 & 8.182 & 0.000 \\
Attitude & 0.781 & 0.095 & 0.663 & & & \\
\hline
\end{tabular}

Note. Dependent Variable: intention.

\section{Discussion}

Many previous studies have recognized the cross-cultural factors as important determinants of e-commerce usage intention. In this regard, this paper extends the existing knowledge on the moderating effect of uncertainty avoidance on e-commerce usage intention between two culturally different countries, Malaysia and Algeria. Understanding these differences would lead us to better understand the key to a successful e-commerce adoption, especially for businesses that are aiming to expand their operations not only in these two countries, but to any other countries with similar cultural traits.

Subjective norm, an important variable driving individuals' behavior, was found to be weakly related to e-commerce usage intention for individuals in high uncertainty avoidance culture, compared to those in low uncertainty avoidance culture. This finding is consistent with a previous study which investigated two different countries, Greece and the United States of America (Chai \& Pavlou, 2004). However, subjective norm was found to have a significant influence on the intention to use e-commerce for the entire data of the two countries, unlike attitude, which did not have a significant influence on the intention to use e-commerce.

On the other hand, uncertainty avoidance was found to influence the relationship between perceived usefulness and attitude, but not on the relationship between subjective norm and attitude. The findings of this research suggest that individuals in a high uncertainty avoidance culture would show a weaker orientation toward e-commerce usefulness-intention relationship, confirming previous findings (Choi \& Geistfeld, 2004). These results highlight the hidden cultural diversity benefits that may be gained from the e-commerce adoption instead of the usual benefit of cognitive and norms attributes.

Another important finding was that there was no influence of uncertainty avoidance on the relationship between subjective norm and intention. This may be explained by differences of ICT skills that exist between Malaysia and Algeria, which lead to a different attitude for the tourism operators to involve e-commerce in their business operations (Belkhamza \& Wafa, 2009). The same thing can be said for the third hypothesis when the results also showed no influence of uncertainty avoidance on the relationship between attitude and intention. Although these results confirm previous findings (Chai \& Pavlou, 2004), it could be explained by the existence of some other factors that may provide a potential understanding on these relationships between these variables, where the cultural effect is lacking and need further investigation.

\section{Theoretical and Managerial Implications}

The objective of this paper was to provide a new understanding of the cultural effect on the e-commerce adoption model in two countries, rarely studied, Malaysia and Algeria. The paper applies an important cultural 
dimension, uncertainty avoidance, aiming to contribute to the application of e-commerce adoption in a broader cross-cultural context. The findings of this research validate new insights of the cultural differences between Malaysia and Algeria, and how e-commerce models may be adopted and perceived. These findings may be very important for companies and international traders in both countries that are thinking on technology transfer and engaging in online business by opening e-commerce businesses. Such technologies often presuppose values that run counter to local cultures (Panina \& Aiello, 2005).

It is also important for those companies to set respective approaches and tailor specific marketing strategies according to the targeted market culture. We therefore call for more collaborative work between companies working in both countries to assist each other in this borderless global business. In both cultures, there exists a strong relationship between usefulness and e-commerce usage intention. This is a good advantage for companies in the two countries to invest this opportunity in order to enhance their business performance according to the local identity of each country, and determine which marketing strategies and presence can be beneficial for their business in various geographical locations globally.

\section{Limitations and Suggestions for Future Research}

Like any other research, some limitations are observed and may assist in paving the way for future research. First, this research was taken tourism operators as unit of analysis. Although the tourism industry pioneers the e-commerce business, many other industries may be taken into consideration to catch the aggregate context of culture, which the tourism industry may not catch, considering those tourists' behaviors toward e-commerce is more globalized than localized toward their respective cultures or countries. Future research may consider studying other industries such as general e-retail websites and online shopping, where a clear distinction between products and services is emphasized and observed. Secondly, only uncertainty avoidance was researched. Future research may consider exploring other cultural dimensions that may have other impacts of the existing cultural differences on the e-commerce acceptance. This may provide a deeper understanding on how people adopt and use e-commerce in different setting globally. Multiple countries may also be involved in future studies with various degrees of cultural variation across Hofstede's dimensions.

\section{References}

Adams, D. A., Nelson, R. R., \& Todd, P. A. (1992). Perceived Usefulness, Ease of Use, and Usage of Information Technology: A Replication. MIS Quarterly, 16(2), 227-247. http://dx.doi.org/10.2307/249577

Ajzen, I. (1991). The Theory of Planned Behavior. Organizational Behavior and Human Decision Processes, 50,179-211. http://dx.doi.org/10.1016/0749-5978(91)90020-T

Al Kailani, M., \& Kumar, R. (2011). Investigating Uncertainty Avoidance and Perceived Risk for Impacting Internet Buying: A Study in Three National Cultures. International Journal of Business and Management, 6(5), 76-92. http://dx.doi.org/10.5539/ijbm.v6n5p76

Belkhamza, Z., \& Wafa, S. A. (2009). Cultural interpretation of e-commerce acceptance in developing countries: Empirical evidence from Malaysia and Algeria. In K. Rouibah, O. Khalil, \& A. E. Hassanien (Eds.), Emerging markets and e-commerce in developing economies (pp. 193-209). Hershey, PA: Information Science Reference. http://dx.doi.org/10.4018/978-1-60566-100-1.ch009

Chai, L., \& Pavlou, P. A. (2004). From “Ancient" to "Modern": a Cross-cultural Investigation of Electronic Commerce Adoption in Greece and the United States. The Journal of Enterprise Information Management, 17(2), 416-423. http://dx.doi.org/10.1108/17410390410566706

Chakraborty, I., Hu, P. J. H., \& Cui, D. (2008). Examining the Effects of Cognitive Style in Individuals' Technology Use Decision Making. Decision Support Systems, 45(2), $228-241$. http://dx.doi.org/10.1016/j.dss.2007.02.003

Chiasson, M. W., \& Lovato, C. Y. (2001). Factors Influencing the Formation of a User's Perceptions and Use of a DSS Software Innovation. Data Base for Advances in Information Systems, 32(3), 16-35. http://dx.doi.org/10.1145/506724.506727

Choi, J., \& Geistfeld, L. V. (2004). A Cross-Cultural Investigation of Consumer E-shopping Adoption. Journal of Economic Psychology, 25, 821-838. http://dx.doi.org/10.1016/j.joep.2003.08.006

Davis, F. D. (1989). Perceived Usefulness, Perceived Ease of Use and User Acceptance of Information Technology. MIS Quarterly, 13(3), 319-340. http://dx.doi.org/10.2307/249008

Fishbein, M., \& Ajzen, I. (1975). Belief, Attitude, Intention and Behavior: An Introduction to Theory and Research. Reading, MA: Addison-Wesley. 
Gefen, D. (2000). E-commerce: The Role of Familiarity and Trust. Omega: The International Journal of Management Science, 28(6), 725-737. http://dx.doi.org/10.1016/S0305-0483(00)00021-9

Green, D, T., \& Pearson, J. M. (2011). Integrating website usability with the electronic commerce acceptance model. Behaviour \& Information Technology, 30(2). http://dx.doi.org/10.1080/01449291003793785

Hofstede, G., \& Bond, M. H. (1988). The Confucius Connection: From Cultural Roots to Economic Growth. Organizational Dynamics, 16(4), 4-21. http://dx.doi.org/10.1016/0090-2616(88)90009-5

Hofstede, G. (1980). Culture's Consequences. Beverly Hills, CA: Sage.

Hofstede, G. (1991). Cultures and Organizations: Software of the Mind. London: McGraw-Hill.

Hofstede, G. (2001). Culture's Consequences (2nd ed.). Thousand Oaks, CA: Sage.

Howe, W. (2012). A brief history of the Internet. Retrieved September 28, 2013, from http://walthowe.com/navnet/history.html

Karahanna, E., \& Straub, D. W. (1999). The Psychological Origins of Perceived Usefulness and Ease of Use. Information and Management, 35(4), 237-250. http://dx.doi.org/10.1016/S0378-7206(98)00096-2

Karahanna, E., Polites, G. L., Williams, C. K., Liu, B., \& Seligman, L. (2013). The Influence of Uncertainty Avoidance on Consumer Perceptions of Global E-Commerce Sites. MWAIS 2013 Proceedings, paper 13.

Lederer, A. L., Maupin, D. J., Sena, M. P., \& Zhuang, Y. (2000). The Technology Acceptance Model and the World Wide Web. Decision Support Systems, 29(3), 269-282. http://dx.doi.org/10.1016/S0167-9236(00)00076-2

Lim, W. M., \& Ting, D. H. (2012). E-shopping: an Analysis of the Technology Acceptance Model. Modern Applied Science, 6(4). http://dx.doi.org /10.5539/mas.v6n4p49

McCoy, S., Galletta, D., \& King, W. (2005). Integrating National Culture into IS Research: The Need for Current Individual-level Measures. Communications of the Association for Information Systems, 15, 211-224.

Nasco, S. A., Toledob, E. G., \& Mykytyn, Jr. P. P. (2008). Predicting electronic commerce adoption in Chilean SMEs. Journal of Business Research, 61, 697-705. http://dx.doi.org/10.1016/j.jbusres.2007.06.047

Ndubisi, N. O., Jantan, M., \& Richardson, S. (2001). Is the Technology Acceptance Model Valid for Entrepreneurs? Model Testing and Examining Usage Determinants. Asian Academy of Management Journal, $6(2), 31-54$.

Panina, D., \& Aiello, J. (2005). Acceptance of Electronic Monitoring and its Consequences in Different Cultural Contexts: A Conceptual Model. Journal of International Management, 11(2), 269-292. http://dx.doi.org/10.1016/j.intman.2005.03.009

Pavlou, P. A., \& Fygenson, M. (2006). Understanding and Predicting Electronic Commerce Adoption: an Extension of the Theory of Planned Behavior. MIS Quarterly, 30(1), 115-143.

Pavlou, P. A. (2003). Consumer Acceptance of Electronic Commerce: Integrating Trust and Risk with the Technology Acceptance Model. International Journal of Electronic Commerce, 7(3), 69-103.

Pavlou, P. A., \& Stewart, D. W. (2000). Measuring the Effects and Effectiveness of Interactive Advertising: A Research Agenda. Journal of Interactive Advertising, 1(1), 5-25. http://dx.doi.org/10.1080/15252019.2000.10722044

Pavlou, P. A., \& Chai, L. (2002). What drives electronic commerce across cultures? A cross-cultural empirical investigation of the theory of planned behavior. Journal of Electronic Commerce Research, 3(4), 240-253.

Pfeffer, J. (1982). Organizations and Organization Theory. Boston, MA: Pitman.

Schein, E. (1980) Organizational Psychology (3rd ed.). Englewood Cliffs, NJ: Prentice-Hall. Science, 30(4), 376-396.

Smith, R., Dietz, G., Royne, M. B., Hansen, J. D., Grünhagen, M., \& Witte, C. (2013). A cross cultural examination of online shopping behavior: a comparison of Norway, Germany, and the United States. Journal of Business Research, 66, 328-335. http://dx.doi.org/10.1016/j.jbusres.2011.08.013

Stewart, D. W., \& Pavlou, P. A. (2002). From Consumer Response to Active Consumer: Measuring the Effectiveness of Interactive Media. Journal of the Academy of Marketing Science, 30(4), 376-396. http://dx.doi.org/10.1177/009207002236912

Taylor, S., \& Todd, P. A. (1995). Understanding Information Technology Usage: A Test of Competing Models. 
Information Systems Research, 6(3), 144-176. http://dx.doi.org/10.1287/isre.6.2.144

Venkatesh, V., \& Davis, F. D. (2000). A Theoretical Extension of the Technology Acceptance Model: Four Longitudinal Field Studies. Management Science, 46(2), 186-204. http://dx.doi.org/10.1287/mnsc.46.2.186.11926

Zwass, V. (1998). Structure and Macro-level Impacts of Electronic Commerce: From Technological Infrastructure to Electronic Marketplaces. In Kendall, K. E. (Ed.), Emerging Information Technologies. Thousand Oaks, CA: Sage Publications.

\section{Copyrights}

Copyright for this article is retained by the author(s), with first publication rights granted to the journal.

This is an open-access article distributed under the terms and conditions of the Creative Commons Attribution license (http://creativecommons.org/licenses/by/3.0/). 